\title{
NA COVID-19: RESILIÊNCIA PARA O IDOSO
}

\author{
Anderson Felisberto Cristiano \\ DOI: http://dx.doi.org/10.18616/intcov16
}

Em 30 de janeiro de 2020, com o surgimento do novo vírus chamado covid-19, a Organização Mundial da Saúde (OMS) anunciou urgência para saúde pública internacional. A vida de muitas pessoas vem sofrendo transformações devido às novas medidas de prevenção. Para pessoas acima de 60 anos, o risco de pegar esse vírus, que pode levar a óbito, é muito maior. Dessa forma, os idosos foram surpreendidos com o isolamento social obrigatório para a preservação de sua saúde. O que já era difícil devido às mudanças físicas de degeneração pela idade avançada, a exclusão da sociedade por conta da aposentadoria, as doenças crônicas, a perda de amigos e redução de independência e autonomia, ganhou significado ainda mais duro.

É visto que o isolamento social traz consigo a solidão, e com ela, a depressão, como apontam Cacioppo et al. (2006), em seu artigo intitulado "Loneliness as a specific risk factor for depressive symptoms: cross-sectional and longitudinal analyses". Seus estudos mostram que os níveis de solidão de pessoas acima de 54 anos foram associados a sintomas mais depressivos. Complementam os autores, que idosos podem fugir dos males da solidão mantendo-se ativos, em contato com colegas de grupos sociais, familiares, amigos e compartilhando bons momentos que lhes proporcionem bem-estar. Diante dessa pandemia é necessário que o idoso tenha consciência de que mesmo em isolamento, é possível estar rodeado de amigos e familiares, com ajuda da tecnologia.

Nesse viés, para o idoso, como qualquer outro ser humano, enfrentar consequências de uma pandemia é um tanto desconfortável, mas trata-se de um desafio necessário. E o primeiro desafio é a resiliência. Gerino et al. (2017), no estudo intitulado "Loneliness, resilience, mental health, and qualityof life in old Age: a structural equation model", comentam sobre as formas de diminuir os níveis de angústia e amargura. Para as autoras, com o aumento da resiliência 
e autorrealização, os idosos podem expressar redução do descontentamento trazido pela solidão durante seu isolamento social. Assim, com um elevado grau de resiliência é possível contribuir para a melhora da qualidade de vida física e psicológica diminuindo a ansiedade e a depressão.

Em tempos da covid-19, os idosos utilizam da resiliência com a ajuda dos profissionais da área da educação e da saúde, ressignificam-se aprendendo a mexer em plataformas on-line para dar continuidade em atividades sociais, como aulas de dança pelo Google Meet, postagem de fotos em Instagram, Facebook, encontros e diálogos pelo Zoom e WhatsApp. A solidão é um problema de saúde pública que pode ser amplamente resolvido, mas isso exigirá o total envolvimento e apoio da comunidade.

\section{REFERÊNCIAS}

CACIOPPO, John et al. Loneliness as a specific risk factor for depressive symptoms: cross-sectional and longitudinal analyses. Psychol Aging, [s.l.], v. 21, n. 1, p. 140-151, 2006. Disponível em: https://pubmed.ncbi.nlm.nih.gov/16594799/. Acesso em: 22 jul. 2020.

GERINO, Eva et al. Loneliness, resilience, mental health, and qualityof life in old age: a structural equation model. Front. in Psychol., [s.l.], v. 8, article 2003, p. 1-12, nov. 2017. Disponível em: https://www.frontiersin.org/articles/10.3389/fpsyg.2017.02003/fullhttps://www.ncbi.nlm.nih.gov/pmc/articles/PMC5694593/pdf/fpsyg-08-02003.pdf. Acesso em: 22 jul. 2020. 